\title{
Retention of geochemical signatures during the transformation of aragonite to calcite at elevated temperatures.
}

\author{
RINAT GABITOV $^{1}$, ANH NGUYEN ${ }^{1}$, ANGEL JIMENEZ ${ }^{1}$, \\ DREW DYGERT ${ }^{1}$, JAC VARCO ${ }^{1}$, VARUN PAUL ${ }^{1}$, \\ ALBERTO PEREZ-HUERTA ${ }^{2}$, ARTACHES MIGDISSOV ${ }^{3}$, \\ PADMANAVA DASH ${ }^{1}$ AND BRENDA KIRKLAND ${ }^{1}$ \\ ${ }^{1}$ Mississippi State University \\ ${ }^{2}$ The University of Alabama \\ ${ }^{3}$ Los Alamos National Laboratory \\ Presenting Author: anhvannguyen.2811@gmail.com
}

Transformation of aragonite, a metastable mineral phase at the Earth's surface, to calcite widely occurs in sedimentary or metamorphic systems in the presence of an aqueous phase. Knowledge of how the transformation process affects geochemical signatures of aragonite (a protolith) helps to answer the following questions: 1) How well the geochemical signature of calcite represents that of the protolith? 2) What can be learned about the conditions of the transformation processes?

To investigate the effect of transformation on elemental and stable isotope ratios we conducted a series of experiments using uranium (U) doped $\mathrm{NaCl}$ solutions at temperatures between 120 and $250^{\circ} \mathrm{C}$. Protolith materials consisted of: 1) synthetic (U-free, and $\mathrm{Mg}$ - and Sr-bearing) needle-shaped microcrystals of aragonite $(<5 \mu \mathrm{m}$ in size $)$ and 2$)$ larger chips $(>100 \mu \mathrm{m}$ in size $)$ of natural aragonite. X-ray diffraction showed that microcrystals successfully transformed to calcite within 2 days and scanning electron microscopy yielded a change in crystal size to $>10 \mu \mathrm{m}$ and morphology to rhombohedral. Electron backscatter diffraction of the larger aragonite chips showed that transformation to randomly oriented calcite occurred at the rims and along the cracks, while the core retained the aragonitic crystalline structure.

Isotope-ratio mass spectrometry analyses showed that calcite $\delta^{18} \mathrm{O}$ is controlled by temperature and $\delta^{18} \mathrm{O}$ of solution. The calibration curve of isotope fractionation factor versus temperature is consistent with other studies. Inductively coupled plasma mass spectrometry analyses showed a strong uptake of $U$ by calcite from solution. Inductively coupled plasma optical emission spectroscopy analyses showed that calcite retained $\mathrm{Mg} / \mathrm{Ca}$ and $\mathrm{Sr} / \mathrm{Ca}$ of the protolith by $40-100 \%$, depending on the specific contact area between microcrystalline aragonite and solution. The smaller the specific contact area, the better the retention.

Obtained structural, textural, and geochemical data suggest the transformation of aragonite microcrystals occurred through a mechanism of coupled aragonite dissolution and calcite precipitation, which occurred at the reaction front where mass transport into the fluid reservoir is limited. In the larger chips, the replacement of aragonite by calcite was proceeded by generation of the fractures, which allowed mass transport between the replacement front and the fluid reservoir. 